\title{
Histology and Histochemistry of Pericarp of Grain Legumes: Cajanus cajan, Vigna mungo and Vigna radiata
}

\author{
C. B. Sehgal and Varsha Gandhi ${ }^{1}$ \\ Department of Botany, University of Delhi, Delhi 110 007, India
}

Accepted February 4, 1985

Pericarp or fruit wall of legumes is compared with leaf (Müntz 1973a, b) assuming that it assimilates $\mathrm{CO}_{2}$ and manufactures carbohydrates by photosynthesis (Flinn and Pate 1968, 1970). Also, it is able to reduce nitrate and synthesize amino acids (Schlesier and Müntz 1974). A portion of the reserve metabolites, present in the seed of grain legumes, comes from the pericarp (Sinha 1977).

For the present paper, pericarp from three important grain legumes namely pigeon pea (Cajanus cajan), black gram (Vigna mungo) and green gram (Vigna radiata) were studied. Structure as well as probable function of the pericarp during the entire seed development phase are described using histochemical techniques.

\section{Materials and methods}

The seeds of Cajanus cajan (Linn.) Millsp. local variety and Vigna mungo (Linn.) Hepper were procured from Pulse Division, IARI, New Delhi, while those of Vigna radiata (Linn.) Wilczek were obtained from National Seeds Corporation, New Delhi. The seeds were sown and crops were raised in the departmental botanical garden.

Time for pollination and fertilization were determined. Post-fertilized ovaries were collected at an interval of one day up to the maturity of seeds, by which time the pods split open into two halves. Ovary and fruit walls were fixed either in formalin acetic alcohol (FAA) or in acetic alcohol (AA), stored in $70 \%$ alcohol. The material was embedded in paraffin and $10 \mu \mathrm{m}$ thick sections were cut (Johansen 1940). FAA fixed materials were used for the detection of insoluble polysaccharides (periodic acid Schiff's, PAS, reaction of Jensen 1962) and total proteins (mercuric bromophenol blue, MBB, method of Mazia et al. 1953). Materials fixed in AA were used for nucleic acids detection. Feulgen reaction was used to identify DNA (Kallarackal 1974). RNA was localized by the pyronin Y method of Tepper and Gifford (1962). Tannins were tested by vanillin-hydrochloric acid method of Gardner (1975).

\section{Observations}

Fertilization occurs on the day of pollination and seeds mature by $38-40$ days after pollination (DAP) in Cajanus cajan. In both species of Vigna, pollination and

1 Present address: Biology Department, Rice University, Houston, Texas 77001, U.S.A. 
fertilization occur on the same day and mature seeds are formed 18 and 15 days after pollination in $V$. mungo and $V$. radiata, respectively.

The post-fertilized ovary is a green, elongated structure. With the passage of time the size of the young pod increases and at the close of 30 days in $C$. cajan, 16 days in $V$. mungo and 14 days in $V$. radiata, it attains the maximum size. At maturity the colour of the pod changes from green to brownish-black (Figs. 1A-C).

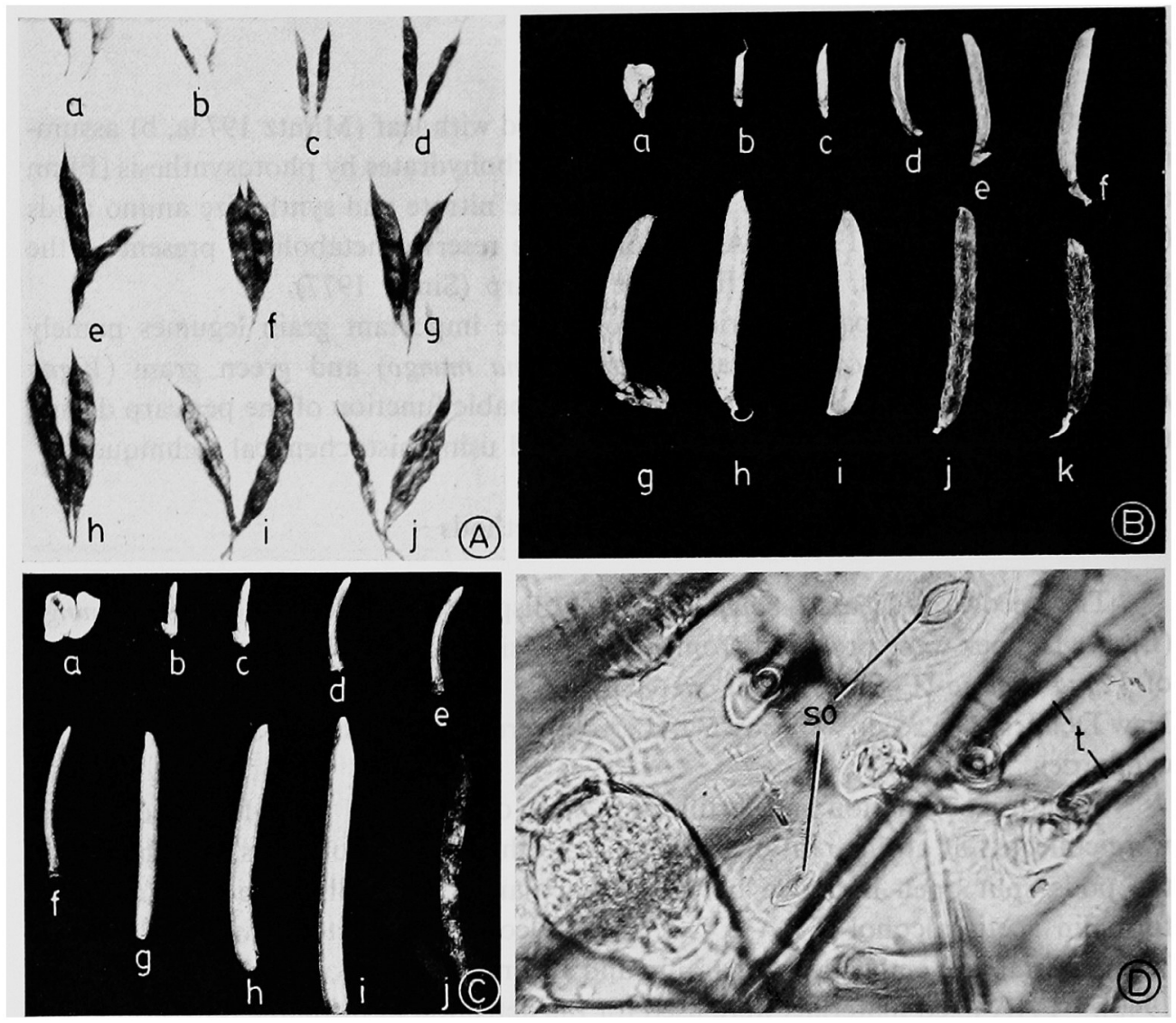

Figs. 1A-D. A-C: Fruits at various stages of development. A, Cajanus cajan a-j: 1, 4, 8, 10, 15, $20,25,30,35$ and $40 \mathrm{DAP}$, respectively. The maximum size is reached $30 \mathrm{DAP}(\mathrm{h}) . \times 0.5$. B, Vigna mungo: a-k, $0,1,2,4,6,8,10,12,14,16$ and 18 DAP. $\times 0.7$. C, $V$. radiata: a, on day of pollination: $\mathrm{b}-\mathrm{j}, 1,2,4,6,8,10,12,14,16 \mathrm{DAP} . \times 0.8$. D, peel-mount of outer epidermis of $C$. cajan showing stomata and trichomes. $\times 700$. (so, stomata; $t$, trichomes.)

The outer most layer of the pericarp is epidermis which bears many stomata and trichomes (Fig. 1D). Internally, pericarp in all the 3 species is composed of 3 zones, the outer, middle and inner or epi-, meso- and endocarp (Figs. 2A, B). During the earlier stages (1-5 DAP) the outer zone is made up of 4-6 layers. The cells are parenchymatous and contain numerous plastids. The middle zone comprises 4-8 layers of elongated and compactly arranged cells. The cells of the inner zone are large, parenchymatous, highly vacuolated and loosely arranged.

In C. cajan, outer and inner zones of pericarp 1 DAP are rich in insoluble 
polysaccharides (starch grains) and only a few grains are present in the middle zone (Fig. 2A). However, all the 3 zones of pericarp, $1 \mathrm{DAP}$, are rich in starch grains in $V$. mungo and $V$. radiata (Fig. 2B). The concentration of starch grains decreases in all the zones 2 and $5 \mathrm{DAP}$ in Vigna species and C. cajan, respectively. In preparations from 5-10 DAP, very few or no starch grains could be localized (Fig. 2C).

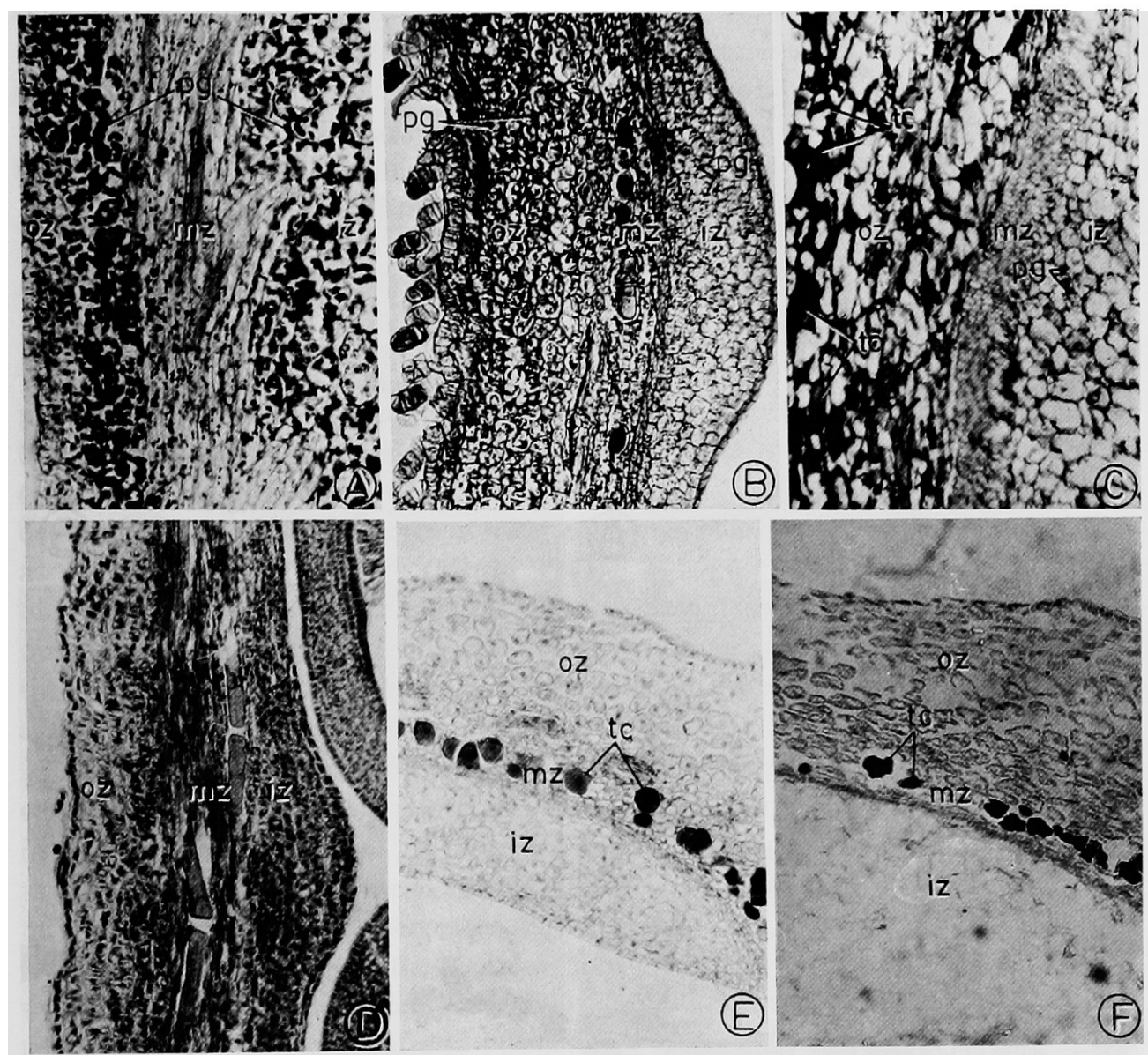

Figs. 2A-F. Longitudinal or transverse sections of portions of pericarps stained with PAS (A-C) and MBB (D-F): A, B, 1 DAP in C. cajan and $V$. mungo, respectively. Note presence of polysaccharide grains in outer and inner zones in $A$ and in all the 3 zones in $B . A \times 365, B \times 128$. C, $V$. mungo 5 DAP, revealing the presence of very few PAS-positive grains only in the inner zone. Note deposition of tannin in the outer zone. $\times 127$. D-F, $V$. radiata 1,2 and $10 \mathrm{DAP}$, respectively and stained with MBB reagent. Note decrease in staining intensity as seed matures. $D \times 225, \mathbf{E}$ $\times 158, \mathrm{~F} \times 126$. (iz, inner zone; $\mathrm{mz}$, middle zone; oz, outer zone; $\mathrm{pg}$, polysaccharide grains; tc, tannin-filled cells.)

One day after pollination, all the 3 zones are rich in total proteins (Fig. 2D). The decrease in protein content follows the same pattern as observed in case of insoluble polysaccharides (Figs. 2E, F).

In C. cajan, 1 DAP, the nuclei of all the 3 zones are moderately stained for DNA. Between 2 and 10 DAP no significant change has been observed in the concentration of DNA. However, a decline in the staining intensity occurs 10 DAP. 


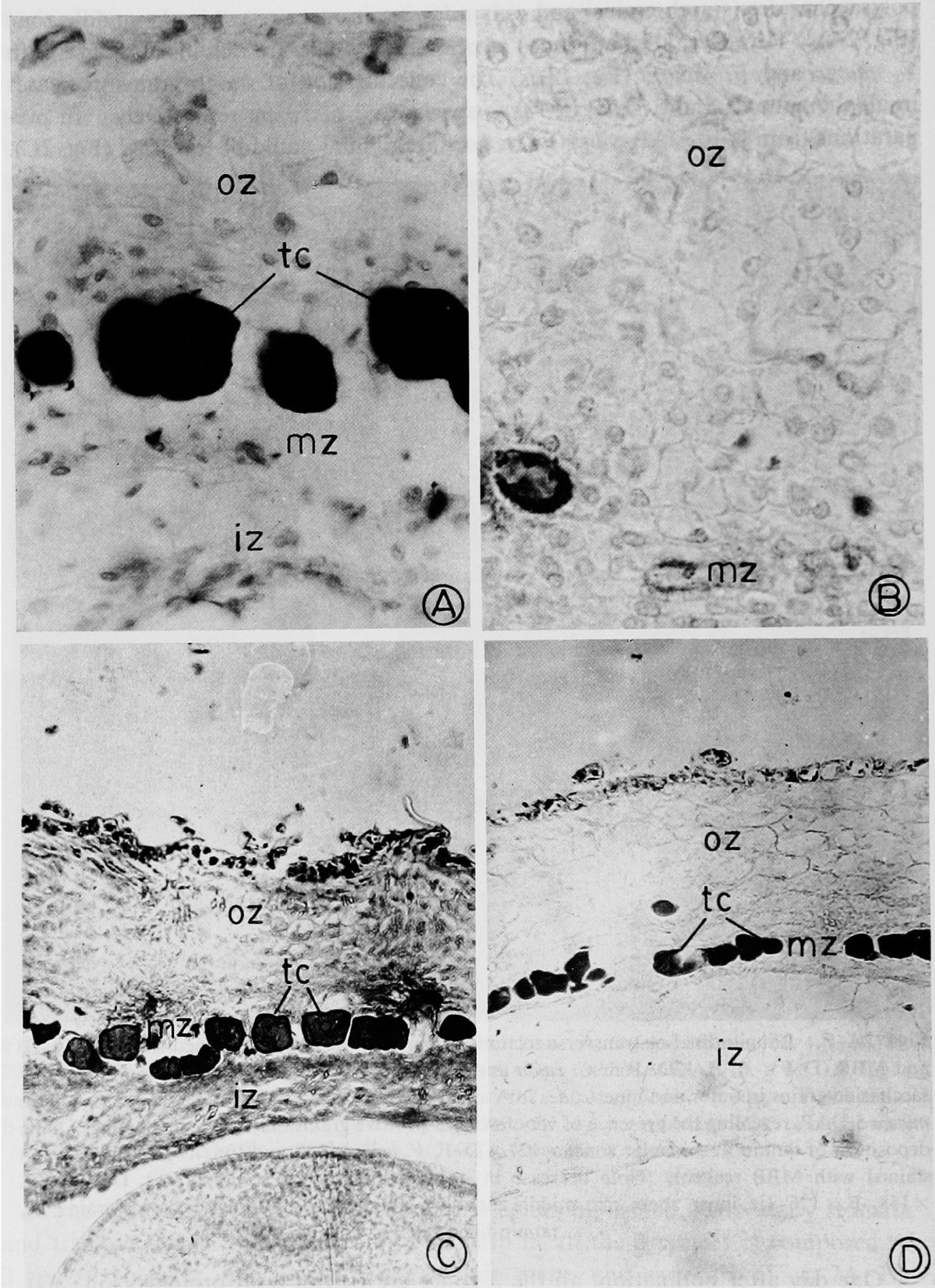

Figs. 3A-D. Longitudinal or transverse sections of portions of pericarp of $V$. radiata stained with Feulgen technique (A, B) and with pyronnin Y (C, D). A, 2 DAP, showing small but densely stained nuclei in all the 3 zones. $\times 416 . \quad B, 5$ DAP. The size of nuclei increases but the staining intensity decreases. $\times 666$. C, 1 DAP, showing moderate level of pyroninophilia in both cytoplasm and nucleoli. $\times 160$. D, 5 DAP. The staining intensity decreases. $\times 155$. (iz, inner zone; mz, middle zone; oz, outer zone; tc, tannin-filled cells.) 
In Vigna species, the nuclei are small and have appreciable amount of DNA, 2 DAP (Fig. 3A). During the maturation period, they increase in size and the staining intensity decreases (Fig. 3B).

Both cytoplasmic and nucleolar RNA are moderately stained in the pericarp of 1-day-old fruit (Fig. 3C). In C. cajan, the concentration decreases 2 DAP and remains the same up to $10 \mathrm{DAP}$. In $V$. mungo and $V$. radiata the concentration remains the same till 2 DAP. Afterwards in all the 3 plants there is a gradual decline and cells of mature pericarp show very low pyroninophilia (Fig. 3D).

Pericarp, 1-5 DAP shows many scattered tanniniferous cells (Fig. 3C). This was also confirmed by vanillin-hydrochloric acid test. In the subsequent stages of development the number of these cells increases.

\section{Discussion}

In all the three taxa (Cajanus cajan, Vigna mungo and $V$. radiata) studied, the pericarp can be differentiated into three zones. These are epi-, meso- and endocarp. Similar observations were also made in Glycine max (Monsi 1943), Pisum sativum (Atkins et al. 1977) and Phaseolus aureus (Savithri and Ganapathy 1978). The endocarp is delimited by a layer of inner epidermis in all three genera (present study) as also observed in Glycine (Monsi 1943). However, Reeve and Brown (1968) observed multilayered epidermis in beans. Although many hair-like extensions are observed on the outer epidermis, no such hairs are present on the inner epidermis of the presently studied genera. The inner epidermis also produces hair-like extensions in Pisum sativum and Vicia faba (Kaniewski 1968).

The presence of large number of stomata in the outer epidermis and chloroplastcontaining cells in the exocarp indicates that this zone of the pericarp must be actively involved in photosynthesis. A large number of PAS-positive grains are observed in the pericarp, especially in the exocarp at the time of fertilization. The concentration of these grains gradually decreases in the exocarp but increases in the endocarp (present study). Later on these grains disappear from the fruit wall but are observed in the integuments (Gandhi 1979). The above observations indicate that the pericarp functions like a leaf and synthesizes carbohydrates which are translocated to the developing seeds.

The functional homology of pericarp and leaf was suggested by Müntz (1973a, b) in Vicia faba. According to him the pods can assimilate $\mathrm{CO}_{2}$ autotrophically (see also Flinn and Pate 1968, 1970). Studies on the pericarp of Pisum sativum by Atkins et al. (1977) indicate that the fruit wall contains two distinct photosynthetic layers. The outer, comprising chlorenchyma of mesocarp, captures $\mathrm{CO}_{2}$ from the outside atmosphere while the inner, a chloroplast-containing epidermis lining the pod gas cavity, is involved in photo-assimilation of $\mathrm{CO}_{2}$ from the fruit cavity.

Not only the carbohydrates but also the amino acids are supposed to be manufactured in the fruit wall. Using the in vivo assay of nitrate reductase it has been established that pericarps of Phaseolus vulgaris and Vicia faba fruits are able to reduce nitrate resulting in the de novo synthesis of amino acids (Schlesier and Müntz 1974). Although a high concentration of total proteins is observed in the pericarp of all 
the three taxa (present study), histochemically it cannot be proved that this is synthesized in the pericarp only. As observed for the carbohydrates, gradual translocation of proteins also occurs from the pericarp to the developing seeds (present study). So the function of pod is not only to synthesize these metabolites but also to act as a reservoir and to translocate them to the developing seeds. This view is in accordance with the conclusions arrived at by Atkins et al. (1977). They have suggested that the carbohydrates produced photosynthetically in fruit wall of pea are translocated to seeds. Sinha (1977) suggested that $25 \%$ of the reserve material in the seed comes from the pericarp. The translocation of amino acids from the pericarp of Vicia faba occurs at the time of protein storage in the cotyledons (Schlesier and Müntz 1974).

Besides carbohydrates and proteins the pericarp of legumes acts as a transport link and temporary reservoir for solutes mobilized from vegetative parts to seeds (Mix and Marschner 1976).

A few researchers believe that the seed does not depend on the pod for its nutritional requirements. Oliker et al. (1978) working on the fruits of Phaseolus vulgaris observed that the nitrogen content of the seed increases rapidly during the 3rd week after anthesis, a stage at which the pod growth has already slowed down, and its nitrogen content has reached a plateau. Although the seed seems to be competing with the pod for nitrogen supply, it does not depend on pod for it.

The seed does not depend on the pod also for its photosynthates (Oliker et al. 1978). This is in accord with reports of Hall et al. (1972) and Crookston et al. (1974) for other bean cultivars, and for soybeans (Quebedeaux and Chollet 1975). The main role of the photosynthetic apparatus present in the pod and seeds of the beans might be to refix $\mathrm{CO}_{2}$ released by respiration (Flinn and Pate 1970, Crookston et al. 1974, Harvey et al. 1976).

\section{Summary}

Histochemical localization of insoluble polysaccharides, total proteins, DNA and RNA has been made on developing pod walls of Cajanus cajan, Vigna mungo and Vigna radiata. The concentration of polysaccharides, proteins and nucleic acids is high during the early stages of development, however, it declines gradually as the seed matures. Function of the pericarp, on the basis of the present data and previous studies, is discussed.

\section{Acknowledgements}

Award of a Junior Research Fellowship by University Grants Commission, Centre of Advanced Study in Botany, to one of us (Varsha) is acknowledged.

\section{References}

Atkins, C. A., Kho, J., Pate, J. S., Flinn, A. M. and Steele, T. W. 1977. Photosynthetic pod wall of pea (Pisum sativum L.). Distribution of carbon dioxide-fixing enzymes in relation to pod structure. Pl. Physiol. (Lancaster) 60: 779-786. 
Crookston, R. K., P'Toole, J. and Ozbun, J. L. 1974. Characterization of the bean pod as a photosynthetic organ. Crop Sci. 14: 708-712.

Flinn, A. M. and Pate, J. S. 1968. Biochemical and physiological changes during maturation of fruit of the field pea (Pisum arvense L.). Ann. Bot. 32: 479-495.

- and - 1970. A quantitative study of carbon transfer from pod and subtending leaf to the ripening seeds of the field pea (Pisum arvense L.). J. Exp. Bot. 21: 71-82.

Gandhi, Varsha 1979. Histochemical studies during fruit development and seed germination of Cajanus cajan, Vigna radiata and Vigna mungo. Ph. D. Thesis, Delhi University, Delhi, India.

Gardner, R. O. 1975. Vanillin-hydrochloric acid as a histochemical test for tannin. Stain Technol. 50: 315-317.

Hall, T. C., McLeester, R. C. and Bliss, F. A. 1972. Electrophoretic analysis of protein changes during the development of the French bean fruit. Phytochemistry 11: 647-649.

Harvey, D. M., Hedley, C. L. and Keely, R. 1976. Photosynthetic and respiratory studies during pod and seed development in Pisum sativum L. Ann. Bot. 40: 993-1001.

Jensen, W. A. 1962. Botanical Histochemistry: Principle and Practice. W. H. Freeman \& Co., London.

Johansen, D. A. 1940. Plant Microtechnique. McGraw-Hill Book Company, New York.

Kallarackal, J. 1974. A modified Schiff reagent for use in Feulgen reaction. Curr. Sci. 43: 120-121.

Kaniewski, K. 1968. Hairs in the loculus of the broad-bean (Vicia faba L.) fruit. Bull. Acad. Polon. Sci. Cl. V. 41 : 585-594.

Mazia, D., Brewer, P. A. and Alfert, M. 1953. The cytochemical staining and measurement of protein with mercuric bromphenol blue. Biol. Bull. 104: 57-67.

Mix, G.P. and Marschner, H. 1976. Calcium-Umlagerung in Bonhen Früchten während des Samenwachstums. Z. Pfiphysiol. 80: 354-366.

Monsi, M. 1943. Untersuchungen über den Mechanismus der Schleuderbewegung der SojabohnenHülse. Jap. J. Bot. 12: 437-474.

Müntz, K. D. 1973 a. Die Funktion der Hülsenschale bei der Proteinspeicherung in den Samen von Vicia faba L. I. Gel-elektrophoretischer Vergleich von löslichen Proteinen aus Blättern und Hülsen. Biochem. Physiol. Pflanzen 164: 357-369.

- 1973 b. Die Funktion der Hülsenschale bei der Proteinspeicherung in den Samen von Vicia faba L. II. Vorkommen eineger Hydrolasen während der Hülsenentwicklung bei Vicia faba L. Biochem. Physiol. Pflanzen 16: 370-382.

Oliker, M., Mayber, A. P. and Mayer, A. M. 1978. Changes in weight, nitrogen accumulation, respiration and photosynthesis during growth and development of seeds and pods of Phaseolus vulgaris. Am. J. Bot. 65: 366-371.

Quebedeaux, B. and Chollet, R. 1975. Growth and development of soybean (Glycine max (L.) Merr.) pods: $\mathrm{CO}_{2}$ exchange and enzyme studies. Pl. Physiol. (Lancaster) 55: 745-748.

Reeve, R. M. and Brown, M. S. 1968. Histological development of the green bean pod as related to culinary texture 1. Early stages of pod development. 2. Structure and composition at edible maturity. J. Food Sci. 33: 321-331.

Savithri, K. S. and Ganapathy, P. S. 1978. Fruit and seed development in mung beans (Phaseolus aureus Roxb.). J. Agric. Sci. 90: 551-556.

Schlesier, G. and Müntz, K. 1974. The function of the pod at protein storage in the seeds of Vicia faba L. III. Nitrate reductase in developing pods and seeds of Leguminosae. Biochem. Physiol. Pflanzen 166: 87-93.

Sinha, S. K. 1977. Food legumes: distribution adaptability and biology of yield. FAO Plant Production and Protection, Paper 3 FAO, Rome.

Tepper, H. B. and Gifford, E. M. Jr. 1962. Detection of ribonucleic acid with pyronin. Stain Technol. 37: 52-53. 